\title{
OPERATIONAL SCENARIO OF COBOT FOR ESCORT OF THE MOBILITY HANDICAPPED AT RAILWAY STATIONS
}

\author{
JONG-GYU HWANG, KYEONG-HEE KIM, TAE-HYUNG LEE, TAE-KI AHN \& MYUNG-SUNG JIN \\ Korean Railroad Research Institute (KRRI), Korea
}

\begin{abstract}
In the case of an urban railway station where several routes are passed by, it is difficult for the railway station user to find their desired path, as it is very complex. Especially in the case of the mobility handicapped and for complex transfer stations, it is difficult for them to find the platform they want to go to, and it is even more difficult to find an available path that includes an elevator or other features to reach a platform where they would want to go, than the general public. Therefore, we think the satisfaction of using railway stations by the mobility handicapped is likely very low in comparison with that of the general public. Accordingly, in this paper we propose the operational scenario of a CoBoT (Collaborative Robot) to provide a system that can follow positioning-based paths within the railway station through which it will guide these mobility handicapped people so they can use railway stations easily with the CoBoT escort service for the mobility handicapped.
\end{abstract}

Keywords: CoBoT, collaborative robot, convenience, handicapped, mobility, mobility handicapped, route guidance system, train station.

\section{INTRODUCTION}

The mobility handicapped is a comprehensive user group that has temporary or continuous restrictions, or inconvenience in movement, when using public transportation facilities due to inconvenience, and actually, all of us are potential mobility handicapped. In the case of Korea, with its entry into being a super-aged society in 2026, it is expected that the mobility handicapped, including the elderly population, will increase remarkably; and it is expected that not only inconvenience factors will increase because of the decline in cognitive ability to judge and due to physical condition, due to the aging, but also their fitness level will be different.

For the elderly who are mobility handicapped, stereoscopic movement and/or transfer itself such as upon use of stairs, escalators, and elevators is an inconvenient matter; and in case of emergency, there is a difference in cognitive response time for them to understand various IoT-based information and escape systems and to escape safely according to instructions. For mobility enhancement for the mobility handicapped, the Mobility Enhancement for the Mobility Handicapped Act [1] has been enacted in Korea, and under the vision of the realization of a society with traffic welfare convenient to all, "the mobility handicapped shall have the right to use all of the transportation means without discrimination, safely and conveniently."

As for the movement restriction issue of the mobility handicapped, in the case of Korea it is our belief that continuous improvement in the satisfaction of use is required, as satisfaction of use within the railway station is very low, although the installation rate of convenient railway facilities for ease of mobility reaches up to $91.7 \%$. Table 1 shows that the satisfaction of use is relatively low compared with the installation rate of convenient facilities for use at railway stations. That is, through the current state data for urban railway, subway and the railway in 2011 and 2016, it was found that, although the average installation rate is at the level of $92 \%$, satisfaction about it falls behind $68 \%$. In the case of passenger facilities other than transportation means, we may see that satisfaction is at a relatively low level, compared with the installation rate of the railway station, because it is about $66-68 \%$ although the 
installation rate is $81-84 \%$. As seen in Table 1, although installation of convenient railway facilities for mobility at the railway station increased, it is our opinion that the satisfaction of use to it is very low; and especially, the mobility handicapped who appeal regarding the many difficulties in using the complex transfer station [2]-[5].

\section{STRUCTURE OF ROUTE GUIDANCE SYSTEM FOR THE MOBILITY HANDICAPPED}

The mobility handicapped (physically challenged person, senior citizen, infant companion, etc.) and general railway users at the railway station need a system that can be connected with a server at anytime and anywhere, and which can provide a safe path for information, provide varied and convenient information, such as the surrounding risk information and more. We propose that the structure of the system be developed so that all railway users, including the mobility handicapped, can receive rapid emergency measures by transmitting their location to related institutions immediately, in case of emergency; and through linking up to the public transportation service and more in the future, so that integrated solutions can be provided to guarantee the right to mobility for all pedestrians, including the mobility handicapped.

Fig. 1 roughly shows the route guidance and support system for these mobility handicapped people at the railway station, and basically, it is a system meant to provide the mobility handicapped with the convenience of mobility and traffic welfare service, based on positioning within the station. To support this service, we have a plan that consists of CoBoT for the mobility handicapped, a station map creation module, and a control system to create optimal paths.

Although this proposed system consists of a basic proposal for the mobility handicapped, this system was configured to have expendability, so that even general users can use it through dynamic, static data and interface with the railway. Fig. 2 shows a block diagram of the overall system, which was developed in consideration of this expendability.

Table 1: Current state of the installation rate and satisfaction of use and convenience in facilities.

\begin{tabular}{|c|c|c|c|c|c|c|c|}
\hline \multirow{2}{*}{\multicolumn{2}{|c|}{ Classification }} & \multicolumn{2}{|c|}{$\begin{array}{l}\text { Current state as of end } \\
2011 \\
\end{array}$} & \multicolumn{2}{|c|}{$\begin{array}{c}\text { Current state as of end } \\
2016 \\
\end{array}$} & \multicolumn{2}{|c|}{ Remarks } \\
\hline & & $\begin{array}{l}\text { Installation } \\
\text { rate }\end{array}$ & Satisfaction & $\begin{array}{l}\text { Installation } \\
\text { rate }\end{array}$ & Satisfaction & $\begin{array}{c}\text { Installation } \\
\text { rate }\end{array}$ & Satisfacticn \\
\hline \multirow{6}{*}{$\begin{array}{l}\text { Passenger } \\
\text { facilities }\end{array}$} & $\begin{array}{c}\text { Passenger car } \\
\text { termingl }\end{array}$ & 43 & 56 & 54 & 60 & $\Delta 11$ & $\boldsymbol{\Delta} 4$ \\
\hline & $\begin{array}{l}\text { Urban railway } \\
\text { and subway } \\
\text { station }\end{array}$ & 78 & 64 & 84 & 68 & $\boldsymbol{\Delta} 6$ & $\Delta 4$ \\
\hline & Railway station & 73 & 62 & 81 & 66 & $\Delta 8$ & $\boldsymbol{\Delta} 4$ \\
\hline & $\begin{array}{l}\text { Airport } \\
\text { passenger } \\
\text { termingl }\end{array}$ & 80 & 66 & 81 & 68 & $\mathbf{\Delta 1}$ & $\Delta 2$ \\
\hline & $\begin{array}{c}\text { Passenger ship } \\
\text { termingl }\end{array}$ & 64 & 58 & 68 & 60 & $\boldsymbol{\wedge} 4$ & $\boldsymbol{\Lambda} 2$ \\
\hline & Bus stop & 37 & 56 & 39 & 60 & $\Delta 2$ & $\boldsymbol{\Delta} 3$ \\
\hline
\end{tabular}




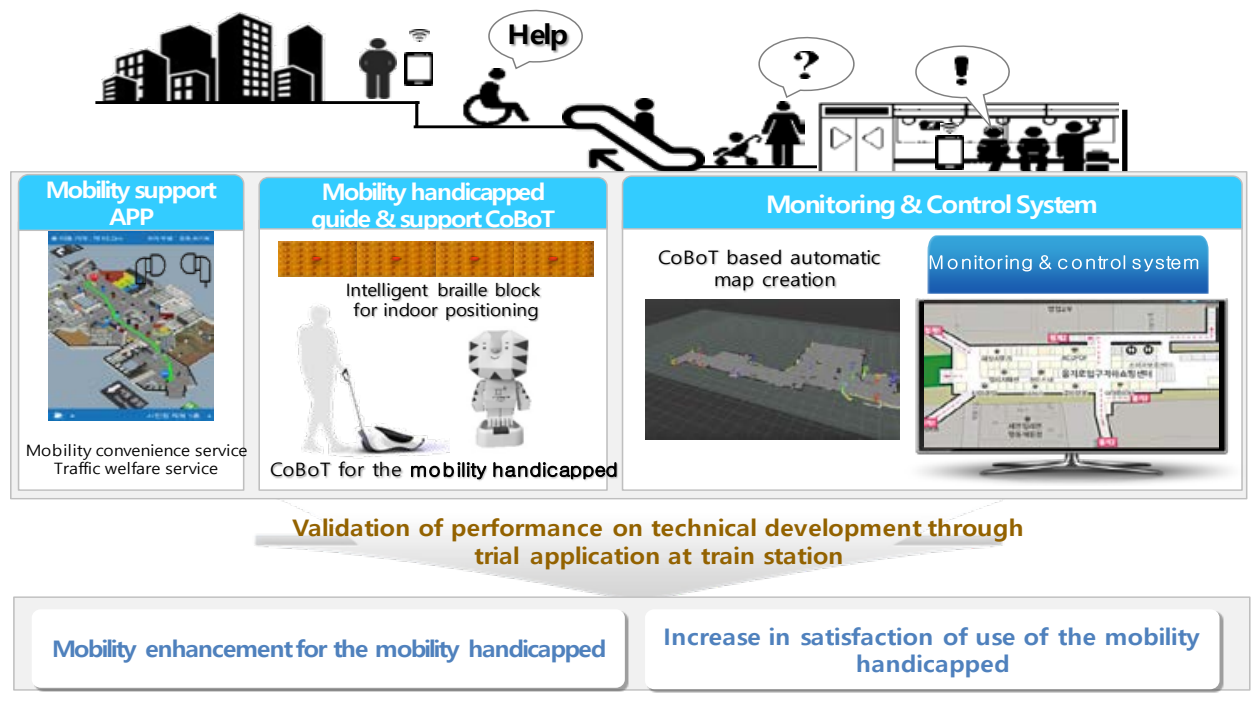

Figure 1: Overview of the proposed system.

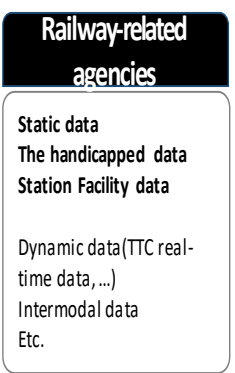

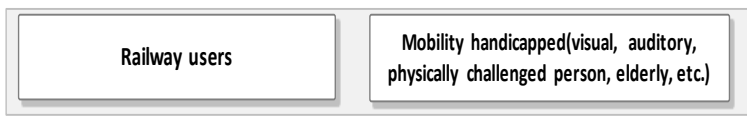

\section{MobileSenice}

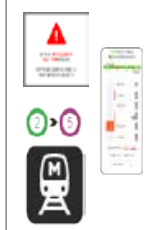

Mobility convenience service Real-time information service

COBoT
nteractive
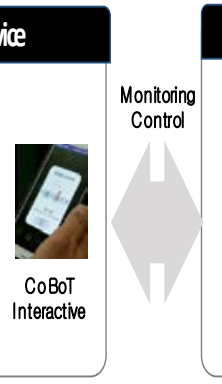

Collaborative Robot(COBoI)

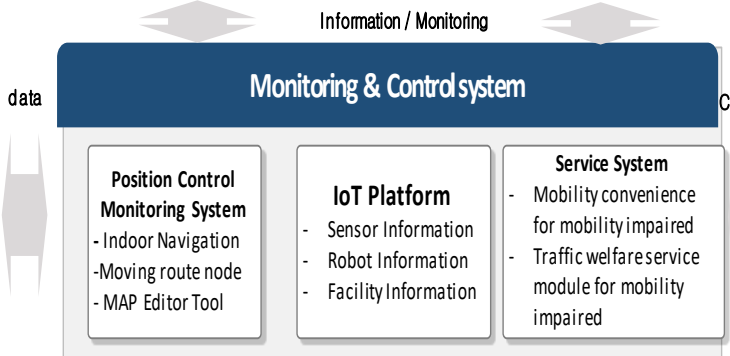

\section{Railwayoperator}

Position control Monitoring Mobility handicapped help service

Emergency alarm

Figure 2: Configuration of the overall system. 


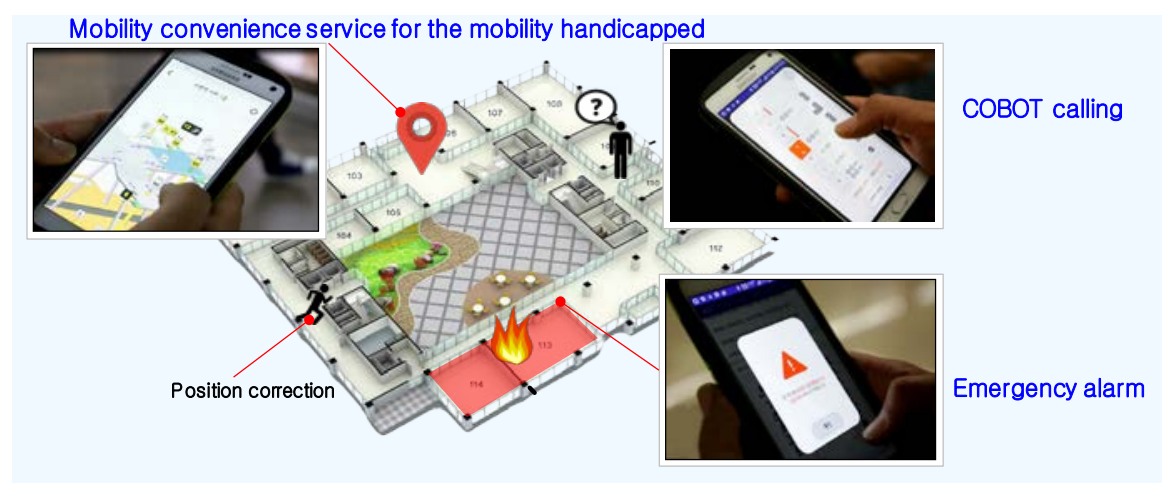

Figure 3: Indoor positioning-based service.

\section{SERVICE SCENARIOS FOR SUPPORTING THE MOBILITY HANDICAPPED}

To improve services for the movement of the mobility handicapped within the railway station, various services such as the service for convenience of mobility, as shown in Fig. 3 where the determination of indoor location is available, escort service through calling for CoBoT, emergency and notification service, etc. in the case of accidents can be provided.

\subsection{Escort service by calling for CoBoT}

If any mobility handicapped person/s should want to have the escort service by CoBoT, then they have to select the escort service when they request service. It is the system where, if any railway mobility handicapped user arrives at the railway station and requests for the escort service of CoBoT, CoBoT would approach the requester, and if the requester orders CoBoT to start services, CoBoT moves along the optimal distance to the destination autonomously, and the requester moves along with this CoBoT. These are shown in Fig. 4. Fig. 5 shows an example of providing an optimal path as the escort service. During the movement towards the destination, information on convenient facilities such as the rest room can be provided, as depicted in Fig. 6.

(1) Type setting (2) Automatic GATE recognition

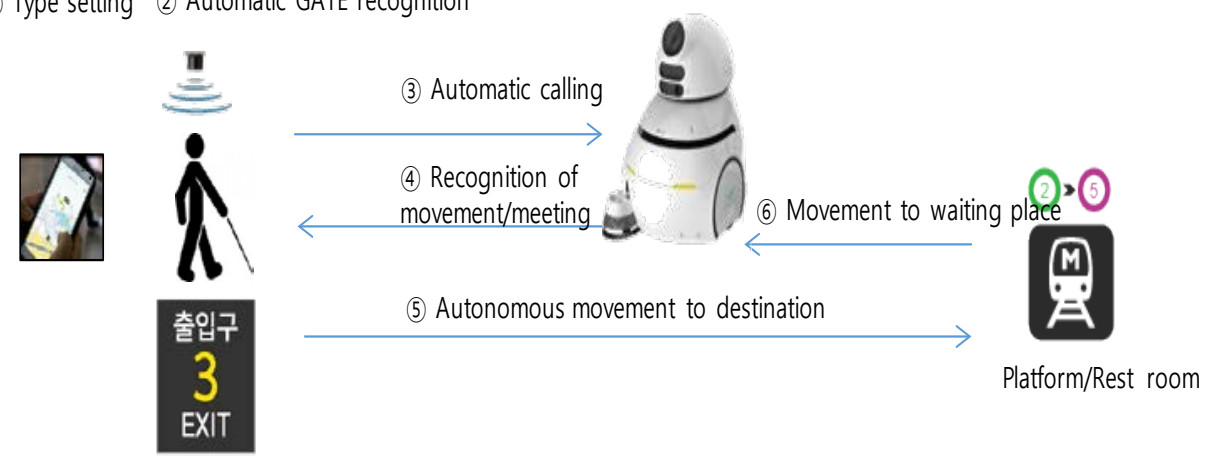

Figure 4: CoBoT escort service. 


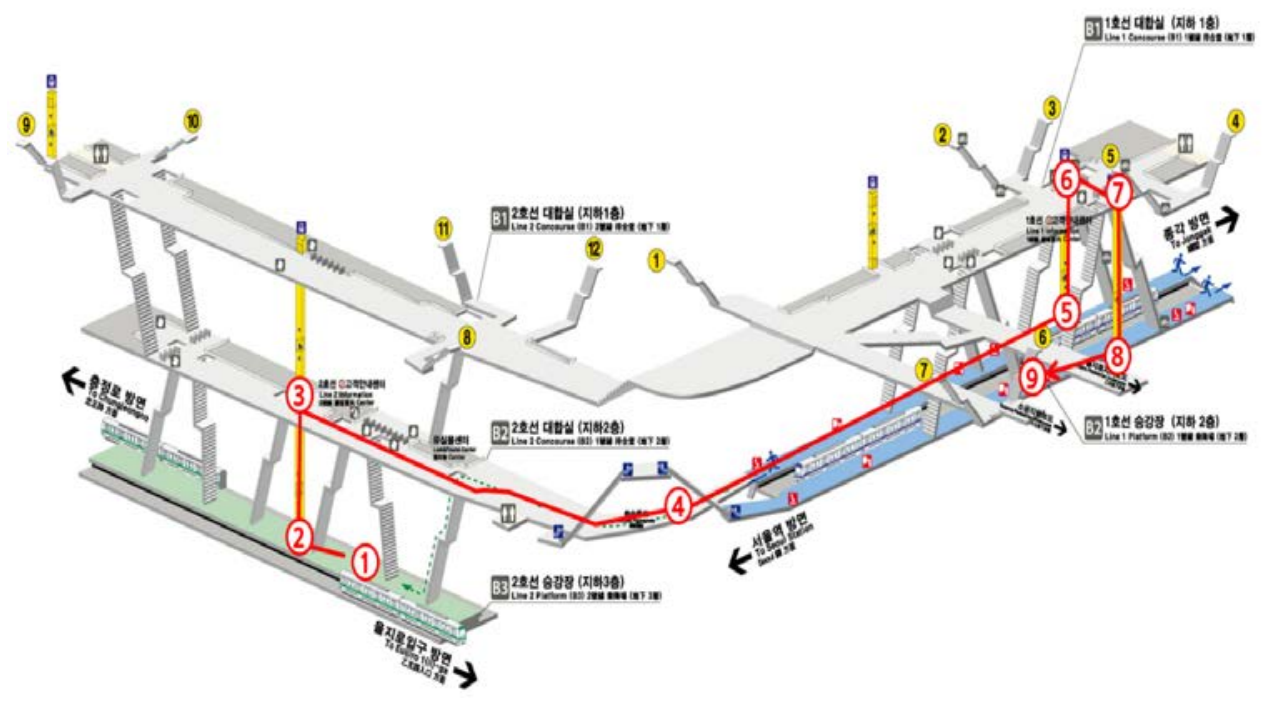

Figure 5: Example of the use of the route guidance mobile app.

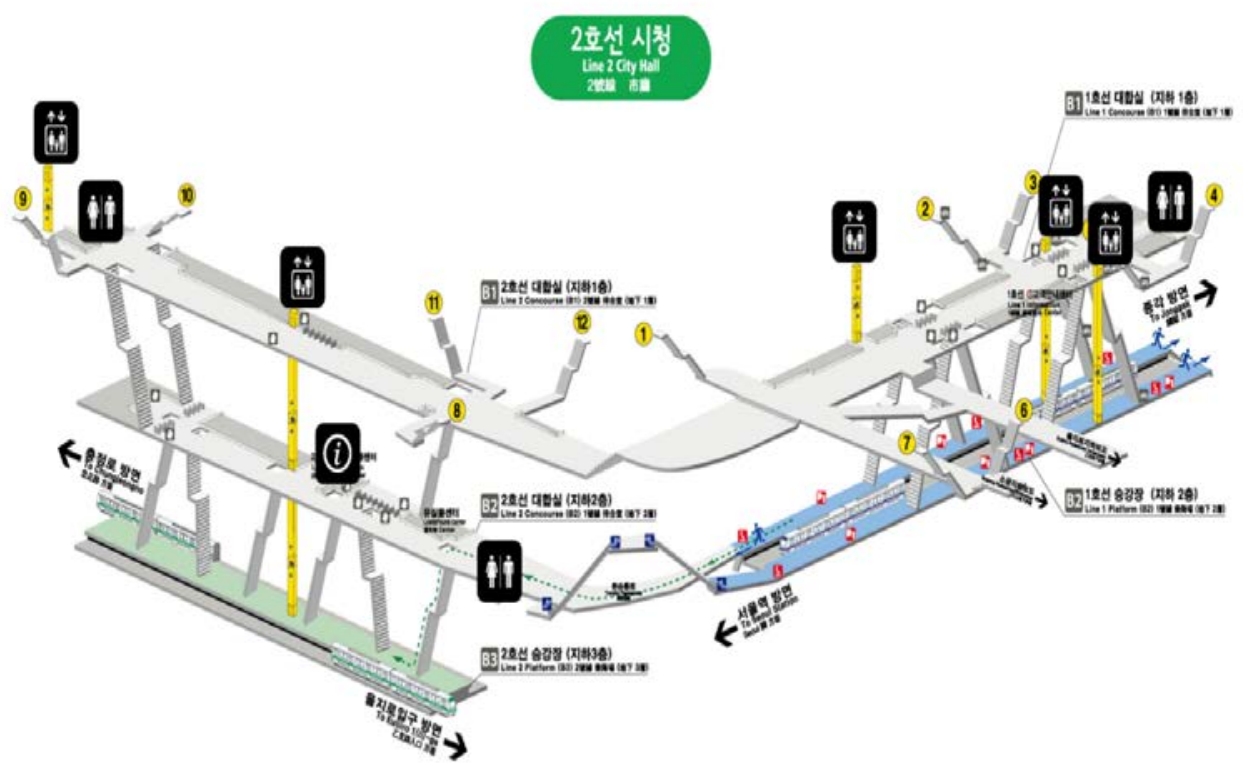

Figure 6: Example of the location announcing app (application) screen for finding convenient facilities within the station. 


\subsection{Emergency service for the mobility handicapped.}

One function is to find out the location of the mobility handicapped and to evacuate them to the safest place, through the mobile app held by CoBoT and the mobility handicapped, in case of an emergency outbreaking within the station, as depicted in Fig. 7. It is this service where the management system monitors the location of the mobility handicapped people within the station, like in Fig. 8, if any mobility handicapped person arrives at the railway station and requests the service, and is guided by the app for the mobility handicapped and CoBoT, to evacuate to the safest destination in case of any outbreaking emergency; and it is designed so that CoBoT can transmit the video of the place where an emergency is occurring or other information measured by environmental sensors, to the management system, if necessary.

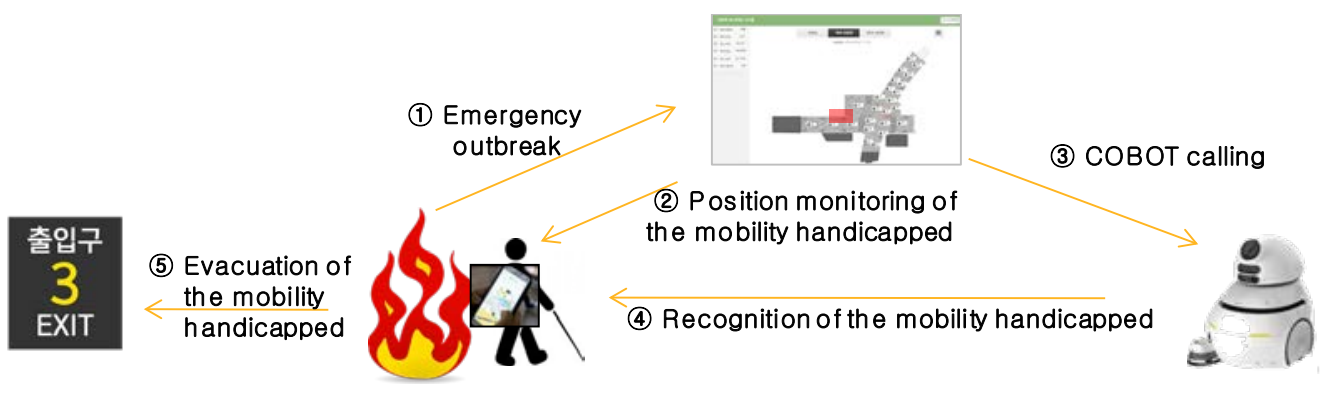

Figure 7: Emergency notification service for the mobility handicapped.

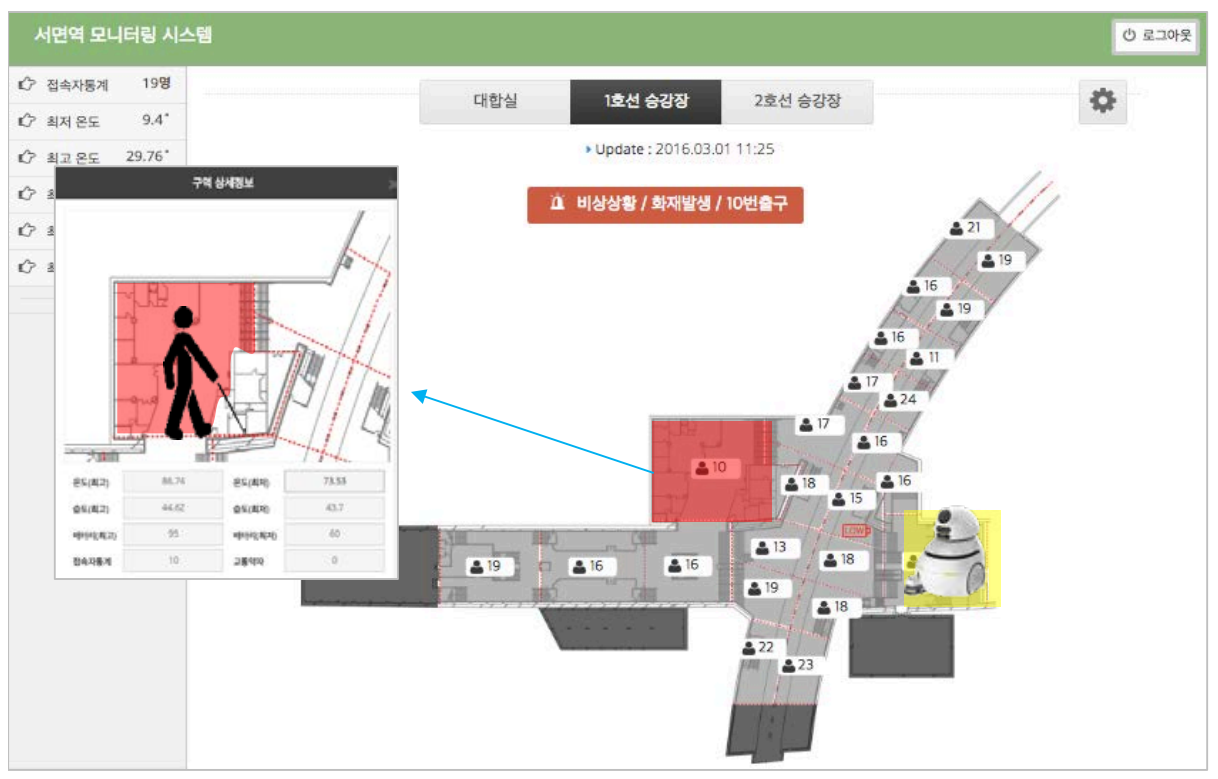

Figure 8: Example of position monitoring screen for the mobility handicapped. 


\section{CONCLUSION}

This paper presents the configuration of the CoBoT-based route guidance and support system which was proposed to enhance user satisfaction of the mobility handicapped patrons at railway stations, a positioning method within the railway station, the operational scenarios of several services on the basis of them, and the mobile app screen where some results were realized. If services using the CoBoT and operational scenarios are eventually realized and used in nationwide railway stations, it is expected that the gap between satisfaction of use between the mobility handicapped people and the general public at railway stations will decrease much. In addition, as a safety service using CoBoT can be provided, it is expected that the system will be an effective model for enhancements in convenience and importantly, enhancement in achieving patron safety.

\section{REFERENCES}

[1] Korean Act, Mobility Enhancement for the Mobility Handicapped Act, 2014. http://www.law.go.kr/lsInfoP.do?lsiSeq=167744\#0000.

[2] Ryu, K.-S., Lee, S.-H. \& Choi, S.-H., The basic study for the mobility enhancement of mobility handicapped in metro. Proceedings of the KSR Spring Conference, 2015.

[3] Co, E.-Y. et. al., Requirements of Navigation Service for the Mobility Impaired Person, 2017.

[4] Ge, T., Indoor Positioning System based on BLE for Blind or Visually Impaired Users. Master's thesis, KTH Royal Institute of Technology, 2015.

[5] https://www.esighteyewear.com. 